\title{
Emerging treatment options for BRAF-mutant colorectal cancer
}

This article was published in the following Dove Press journal: Gastrointestinal Cancer:Targets and Therapy

\section{Carling Ursem \\ Chloe E Atreya \\ Katherine Van Loon \\ Division of Hematology and Oncology, Department of Medicine, University of California, San Francisco, CA, USA}

Correspondence: Katherine Van Loon UCSF Helen Diller Family Comprehensive Cancer Center, 550 16th Street, 6th Floor, Box 321 I, San Francisco, CA 94I43, USA

Tel +l 4158853847

Fax + I 4153537779

Email katherine.vanloon@ucsf.edu

\begin{abstract}
The personalization of cancer care is rooted in the premise that there are subsets of patients with tumors harboring clinically relevant targets for patient-specific treatments. Colorectal cancer (CRC) is a disease that has historically been notable for its dearth of biomarkers that are predictive of response to targeted therapies. In recent years, $B R A F^{\mathrm{V} 600 \mathrm{E}}$-mutated CRC has emerged as a distinct biologic entity, typically refractory to standard chemotherapy regimens approved for the treatment of metastatic CRC and associated with a dismal prognosis. Multiple clinical trials sought to replicate the successes of targeted therapies seen in $B R A F^{\mathrm{V} 600 \mathrm{E}}$ mutated melanoma without success; metastatic $B R A F^{\mathrm{V} 600 \mathrm{E}}$-mutated CRC is clearly a distinct biologic entity. We review a number of recent studies demonstrating the evidence of modest responses to combinations of BRAF, EGFR, and/or MEK inhibition in patients with metastatic $B R A F^{\mathrm{V} 600 \mathrm{E}}$-mutated $\mathrm{CRC}$; however, despite advances, overall survival remains far inferior for these patients compared to their $B R A F$-wild-type counterparts. Development of combination therapies to impede signaling through the $M A P K$ pathway through alternate targets remains an area of active investigation. Reflecting the rapid evolution of efforts for this small subset of CRC patients, the first-ever Phase III study is now underway evaluating the combination of $B R A F$, $E G F R$, and $M E K$ inhibition. Immunotherapies are also an area of active research, particularly for the subset of patients with tumors that are also microsatellite instability (MSI) high. Here, we summarize the current landscape and emerging data on the molecular, clinical, and therapeutic aspects of $B R A F$-mutant CRC.
\end{abstract}

Keywords: colon cancer, BRAF mutation, molecular targets, targeted therapy

\section{Introduction}

Colorectal cancer (CRC) is the third most common cancer worldwide ${ }^{1}$ and the fourth most common cancer in the USA. ${ }^{2}$ Globally, there are $\sim 774,000$ deaths each year from $\mathrm{CRC}^{3}{ }^{3} B R A F$ mutations are present in $\sim 10 \%$ of CRC cases. Although malignant melanoma is a disease more commonly associated with $B R A F^{\mathrm{V} 600 \mathrm{E}}$ mutation, $\mathrm{CRC}$ is a much more prevalent disease and deaths from $B R A F$-mutant CRC are predicted to exceed those from $B R A F$-mutant melanoma. ${ }^{1}$

Moreover, the clinical significance, prognosis, and therapeutic targets of a detected $B R A F$ mutation in metastatic CRC provide a stark contrast to melanoma; the alteration at codon 600 is present in $\sim 50 \%$ of melanoma cases ${ }^{4}$ and is associated with response rates of up to $80 \%$ for treatment with single-agent BRAF inhibitors, including vemurafenib, ${ }^{5}$ dabrafenib,${ }^{6}$ and encorafenib. ${ }^{7}$ While responses to single-agent BRAF inhibitors in metastatic melanoma are not necessarily durable, there is clear biologic activity. 
By comparison, single-agent vemurafenib was found to have a response rate of $\angle 5 \%$ in metastatic $B R A F$-mutant CRC. ${ }^{8}$ In recent years, $B R A F$-mutant $\mathrm{CRC}$ has emerged as a distinct biologic entity, refractory to standard chemotherapy regimens approved for the treatment of metastatic CRC and associated with a dismal prognosis. Here, we summarize the current landscape and emerging data on the molecular, clinical, and therapeutic aspects of $B R A F$-mutant CRC.

\section{The molecular landscape}

$B R A F$ is a serine/threonine kinase immediately downstream of KRAS in the $M A P K$ signaling pathway; thus, mutations in this gene are detected almost exclusively in $K R A S$-wildtype CRC. $B R A F$-mutant CRC typically harbors a valine (V) to glutamic acid (E) change at codon 600 (c.1799T $>$ A or p.V600E). This alteration in the BRAF kinase domain results in a constitutively active protein.

In addition to $\mathrm{CRC}$ and melanoma, the Cancer Genome Atlas identified $B R A F^{\mathrm{V} 600 \mathrm{E}}$ mutations in non-small-cell lung cancer, thyroid cancer, cholangiocarcinoma, and gliomas in addition to some hematologic malignancies. ${ }^{9}$ In a population-based study of CRC, $B R A F^{\mathrm{v} 600 \mathrm{E}}$ mutations strongly associated with hypermutated tumors, frequently exhibiting a $\mathrm{CpG}$ island methylator phenotype (CIMP) and sporadic microsatellite instability (MSI). ${ }^{10}$ The Cancer Genome Atlas similarly identified $B R A F^{\mathrm{V} 600 \mathrm{E}}$ mutations in $3 \%$ of nonhypermutated and $47 \%$ of hypermutated colon cancers ( $\mathrm{n}=165$ and 30 , respectively) ${ }^{11}$ however, these numbers may reflect selection bias and likely overestimate the proportion of BRAF mutations in hypermutated CRC.A study of $218 \mathrm{CRC}$ tumor specimens with $B R A F^{\mathrm{V} 600 \mathrm{E}}$ identified two distinct subgroups independent of MSI status, PI3K mutation, gender, and sidedness. ${ }^{12}$ One subset of tumors was characterized by high KRAS/mTOR/AKT/4EBP1/ EMT activation, while the other was characterized by cell cycle dysregulation. Identification of these two unique subgroups of $B R A F^{\mathrm{V} 600 \mathrm{E}}$ mutations may explain the nonuniform responses seen to drug therapies including $B R A F$ and $M E K$ inhibitors.

Although there are other non-V600E $B R A F$ mutations in $\mathrm{CRC}$ with a different phenotype, none have been identified as strongly prognostic. ${ }^{13} \mathrm{~A}$ study performing next-generation sequencing of CRC from $\sim 10,000$ patients identified nonV600E BRAF mutations in $2.2 \%$ of cases, accounting for $22 \%$ of the total $B R A F$ mutations identified. ${ }^{14}$ In this study, non-V600E BRAF mutations in CRC were associated with younger age, male gender, lower-grade tumor, and less right-sided primaries. Additionally, these mutations were associated with improved overall survival (OS) compared to patients with either wild-type $B R A F$ or $B R A F^{\mathrm{V} 600 \mathrm{E}}$-mutant CRC. A study of 10 patients with $B R A F$ mutations at codons 594 and 596 also found these unique mutations to be conversely associated with improved prognosis. ${ }^{15}$

\section{Unique clinical presentations}

In the early days of understanding BRAF mutant $\mathrm{CRC}$, the clinically defining feature of $B R A F^{\mathrm{V} 600 \mathrm{E}}$ mutation in $\mathrm{CRC}$ was its dismal prognosis. We first observed these patients to be at risk for clinical deterioration after rapid sequential progression through multiple lines of standard chemotherapy. Many patients died while in queue for the first clinical trials offering a hope of personalized therapies.

Since then, we have identified multiple other clinicopathologic features often associated with the $B R A F^{\mathrm{V} 600 \mathrm{E}}$ mutation. Older age, female gender, and White race have been associated with increased likelihood of harboring a $B R A F^{\mathrm{V} 600 \mathrm{E}}$ mutation. ${ }^{16-18}$ Over two-thirds of $B R A F^{\mathrm{v} 600 \mathrm{E}}$ tumors originate in the right colon vs the left colon ( 68 vs $32 \%$ ); this ratio is in contrast to the typical distribution for $B R A F$-wild-type tumors, which occur more frequently in the left colon (35 vs $65 \% ; P<0.001) .{ }^{19}$ An analysis of sites of metachronous metastases found that $B R A F^{\mathrm{V} 600 \mathrm{E}}$ tumors are associated with more frequent peritoneal metastases $(26 \mathrm{vs} 14 \% ; P<0.01)$ and less frequent liver-limited metastatic disease ( 41 vs $63 \% ; P<0.01$ ) at the time of diagnosis. ${ }^{20}$ When observing the entire disease course, significantly higher rates of peritoneal metastases (46 vs $24 \% ; P=0.001)$ and distant lymph node metastases (53 vs $38 \% ; P=0.044$ ) and lower rates of lung metastases (35 vs $49 \% ; P=0.049)$ have been reported in $B R A F^{\mathrm{V} 600 \mathrm{E}}$ tumors. ${ }^{19}$

A retrospective study that matched patients with $B R A F^{\mathrm{v} 600 \mathrm{E}}$-mutant tumors to patients with $B R A F$-wild-type tumors based on tumor location found more peritoneal metastases and ascites in the $B R A F^{\mathrm{V} 600 \mathrm{E}}$-mutant tumors. However, when limiting this comparison to only patients with right-sided primaries, there was no difference in sites of metastasis. ${ }^{21}$ Notably, the increased incidence of peritoneal metastases and ascites represents unique challenges in the interpretation of responses using response evaluation criteria in solid tumors (RECIST 1.1) in the context of clinical trial evaluations. ${ }^{21}$

\section{The prognostic and predictive values of a $B R A F^{\mathrm{V} 600 \mathrm{E}}$ mutation}

Following early clinical observations of the unique disease biology and dramatically inferior survival of patients with metastatic $B R A F^{\mathrm{V} 600 \mathrm{E}}$-mutant $\mathrm{CRC}$, several subset analyses 
from multiple large clinical trials and retrospective series sought to further characterize features of $B R A F^{\mathrm{v} 600 \mathrm{E}}$-mutant CRC. In the MRC COIN trial of a fluoropyrimidine and oxaliplatin with or without cetuximab, the median OS across treatment arms was 20.1 months for patients with $R A S /$ $B R A F$-wild-type tumors vs 8.8 months for patients with tumors harboring $B R A F^{\mathrm{V} 600 \mathrm{E}}$ mutations. ${ }^{22}$ Among patients treated with infusional 5-fluorouracil (5-FU), leucovorin and irinotecan (FOLFIRI), and bevacizumab in the FIRE-3 study, $B R A F^{\mathrm{V} 600 \mathrm{E}}$-mutant tumors were found to have a significantly shorter OS vs those with $B R A F$-wild-type tumors (13.7 vs 20.1 months). ${ }^{23}$ Cancer and Leukemia Group B (CALGB) 80405 was a recent study of the chemotherapy backbones infusional 5-FU, leucovorin and oxaliplatin (FOLFOX), or FOLFIRI with the addition of either bevacizumab or cetuximab in metastatic CRC. ${ }^{24}$ Among patients receiving chemotherapy plus bevacizumab, a subset analysis demonstrated a median OS of 17.4 months in patients with $B R A F^{\mathrm{V} 600 \mathrm{E}}$ mutations vs 35.1 months in $B R A F$-wild-type patients. ${ }^{25}$

Outside of the clinical trial setting, a retrospective study of patients at two major academic centers showed a decreased median OS in patients with $B R A F^{\mathrm{V} 600 \mathrm{E}}$ mutations of $10.4 \mathrm{vs}$ 34.7 months $(P<0.001) .{ }^{19}$ Additionally, an analysis of patients with metastatic CRC in the Nurses' Health Study and Health Professionals' Follow-up Study found that among patients with microsatellite stable (MSS) tumors, a $B R A F^{\mathrm{v} 600 \mathrm{E}}$ mutation was associated with a colon cancer-specific mortality hazard ratio (HR) of $1.60(95 \% \mathrm{CI}=1.12-2.28 ; P=0.009) .{ }^{26}$

Because $B R A F$ testing is not routinely performed in nonmetastatic $\mathrm{CRC}$, less is known about the prognostic and predictive values of $B R A F$ mutations in this setting; however, retrospective studies from adjuvant chemotherapy trials have provided some insight. In a retrospective analysis of tumor samples collected from stages II and III CRC patients in the adjuvant PETACC-3 study, $B R A F^{\mathrm{V} 600 \mathrm{E}}$ mutations were identified in $7.9 \%$ of patients, ${ }^{27}$ similar to what is seen in metastatic disease. $B R A F^{\mathrm{V} 600 \mathrm{E}}$ mutation was associated with decreased OS (HR 1.66; 95\% CI 1.15-2.40) in both stages II and III patients, with an even more pronounced effect in the MSS cohort with $B R A F^{\mathrm{V} 600 \mathrm{E}}$ mutations (HR 2.19;95\% CI 1.43-3.37). A similar analysis of tumor samples from 2720 stage III patients treated on the NCCTG N0147 adjuvant study found that $B R A F^{\mathrm{V} 600 \mathrm{E}}$ mutation was associated with worse 5-year disease-free survival (HR 1.43; 95\% CI $1.11-1.85) .{ }^{27}$ In a retrospective study of 364 stages II and III patients treated in the Netherlands, a $B R A F^{\mathrm{V} 600 \mathrm{E}}$ mutation was detected in $22 \%$ of stage II and $19 \%$ of stage III patients. ${ }^{27}$ In a multivariate model, $B R A F^{\mathrm{V} 600 \mathrm{E}}$ was similarly associated with worse OS (HR 0.45; 95\% CI 0.25-0.8) and cancer-specific survival (HR 0.47, 95\% CI 0.22-0.99). Based on these studies, it is thought that $B R A F^{\mathrm{V} 600 \mathrm{E}}$ mutation remains associated with poor prognosis in stages II and III CRC; however, we do not have data to substantiate whether or not it is predictive of benefit from adjuvant chemotherapy.

Because $R A S$ and $B R A F^{\mathrm{V} 600 \mathrm{E}}$ mutations are typically mutually exclusive at diagnosis, patients with $B R A F^{\mathrm{V} 600 \mathrm{E}}$ mutations were naively included in clinical trials of the anti-epidermal growth factor receptor (EGFR) therapies, cetuximab and panitumumab, which recruited patients with $K R A S$-wild-type tumors. An initial pooled analysis of 70 cases with $B R A F^{\mathrm{V} 600 \mathrm{E}}$ mutations from the CRYSTAL and OPUS randomized clinical trials found that the addition of cetuximab to first-line chemotherapy was possibly associated with a nonsignificant trend toward improved progression-free survival (PFS) and OS for $B R A F^{\mathrm{V} 600 \mathrm{E}}$-mutant metastatic CRC, although inferior OS was observed across treatment arms in comparison to $B R A F$-wild-type patients. ${ }^{28}$

However, a large meta-analysis of $463 B R A F^{\mathrm{v} 600 \mathrm{E}}$ tumors from one Phase II and nine Phase III trials of cetuximab or panitumumab did not show a PFS (HR 0.88; 95\% CI $0.67-1.14 ; P=0.33)$ or an OS (HR, 0.91; 95\% CI 0.62-1.34; $P=0.63$ ) benefit compared to the control chemotherapy arms. ${ }^{29}$ Another meta-analysis of $351 B R A F^{\mathrm{V} 600 \mathrm{E}}$ mutant tumors from eight randomized trials (seven with OS data) similarly did not identify an advantage for anti-EGFR therapy over the control arm for either PFS (HR 0.86; 95\% CI 0.61-1.21) or OS (HR $0.97 ; 95 \%$ CI $0.67-1.41) .{ }^{30}$ Although the interaction between $B R A F^{\mathrm{V} 600 \mathrm{E}}$ status and treatment response was not significant $(P=0.43)$ and the authors concluded that the results could be due to chance alone, ${ }^{30}$ the preponderance of data suggests that patients with $B R A F^{\mathrm{V} 600 \mathrm{E}}$ mutations are unlikely to derive significant benefit from the currently approved anti-EGFR regimens. In line with this, current National Comprehensive Cancer Network (NCCN) consensus-based guidelines advise that the presence of a $B R A F^{\mathrm{V} 600}$ mutation confers a very low likelihood of response to anti-EGFR therapy. ${ }^{31}$

\section{Revisiting a role for cytotoxic chemotherapy}

Secondary analyses of $B R A F^{\mathrm{V} 600 \mathrm{E}}$-mutant subsets from multiple randomized clinical trials demonstrating a lack of therapeutic benefit and bleak prognosis with conventional cytotoxic chemotherapy doublets ${ }^{32}$ subsequently spurred attempts at identifying alternative treatment options for patients with metastatic $B R A F^{\mathrm{V} 600 \mathrm{E}}$ mutant $\mathrm{CRC}$. Given the aggressive nature of $B R A F^{\mathrm{V} 600 \mathrm{E}}$ disease, clinicians are often 
faced with the challenge of achieving initial disease control in patients at risk for rapid clinical deterioration. ${ }^{33}$

The TRIBE study evaluated FOLFIRI plus bevacizumab vs infusional 5-FU, leucovorin, and oxaliplatin and irinotecan (FOLFOXIRI) plus bevacizumab. ${ }^{34}$ Of the 508 patients in this study, 28 patients with $B R A F^{\mathrm{V} 600 \mathrm{E}}$ mutations were enrolled, of whom 12 patients were assigned to the FOLFIRI arm and 16 patients were assigned to the FOLFOXIRI arm. Across both arms, the median OS in the $R A S$ - and $B R A F$-wild-type patients was 37.1 vs 13.4 months in the small subset of patients with tumors harboring $B R A F^{\mathrm{V} 600 \mathrm{E}}$ mutations (HR $2.79 ; 95 \%$ CI $1.75-4.46 ; P<0.0001) .{ }^{35}$ Although the number of patients with $B R A F^{\mathrm{v} 600 \mathrm{E}}$ mutations in this study was small, the median OS of patients treated with FOLFOXIRI plus bevacizumab in TRIBE was 19.0 months compared to 10.7 months in the FOLFIRI plus bevacizumab arm (HR 0.54 ; 95\% CI 0.24-1.20). ${ }^{35}$ An overall response was reported in $56 \%$ of patients with a $B R A F^{\mathrm{V} 600 \mathrm{E}}$ mutation receiving FOLFOXIRI plus bevacizumab vs $42 \%$ of patients receiving FOLFIRI plus bevacizumab (odds ratio [OR] 1.82, 95\% CI 0.91-2.62). There was no significant association between treatment effect and $B R A F$ mutation status either for OS $(P$-value $=0.52)$ or for PFS $(P$-value $=0.68),{ }^{35}$ suggesting that patients with $B R A F^{\mathrm{V} 600 \mathrm{E}}$ mutations derived equivalent benefit from FOLFOXIRI over FOLFIRI as their $B R A F$-wild-type counterparts. In the CHARTA Phase II study, in patients with $B R A F^{\mathrm{V} 600 \mathrm{E}}$ mutations, the median PFS was 10.1 months among patients who received FOLFOXIRI plus bevacizumab vs 7.8 months in patients who received FOLFIRI plus bevacizumab (HR 0.72, $P=0.61$ ). ${ }^{36}$ Acknowledging the limitations of the small sample size in both of these studies and the lack of statistical significance of the trend toward benefit, FOLFOXIRI plus bevacizumab is an option for patients with known metastatic $B R A F^{\mathrm{V} 600 \mathrm{E}} \mathrm{CRC}$ with well-preserved performance status for whom early disease control is urgent and imperative. Additionally, based on data from Loupakis et $a{ }^{17}$ showing that female patients with right-sided primary tumors with mucinous histology have an $81 \%$ chance of having a $B R A F^{\mathrm{v} 600 \mathrm{E}}$ mutation, we consider upfront triplet therapy in patients who meet some of these criteria, while molecular analyses are pending.

Although $B R A F$ mutation status was not assessed at the time of the clinical trials that led to the approval of bevacizumab in metastatic CRC, it is generally thought that $B R A F^{\mathrm{V} 600 \mathrm{E}}$ does not preclude response to bevacizumab. As noted earlier in the TRIBE study, significant response has been seen with triplet chemotherapy in combination with bevacizumab. ${ }^{34}$ Additionally, a subgroup analysis of
$B R A F^{\mathrm{V} 600 \mathrm{E}}$-mutated tumors from CAIRO3 showed a preserved benefit from bevacizumab containing maintenance therapy compared to no maintenance as compared to patients with wild-type tumors. ${ }^{37}$ However, bevacizumab is highly unlikely to overcome the negative prognostic effect of a $B R A F^{\mathrm{V} 600 \mathrm{E}}$ mutation; a retrospective study of patients treated with FOLFOX plus bevacizumab found the overall response rate in patients with a $B R A F^{\mathrm{V} 600 \mathrm{E}}$ mutation to be only $18.4 \% .{ }^{38}$

\section{Developing a personalized approach}

Since $B R A F^{\mathrm{V} 600 \mathrm{E}} \mathrm{CRC}$ emerged as a distinct entity, multiple clinical trials have sought to replicate the successes of targeted therapies seen in melanoma (Table 1). The two BRAF inhibitors, vemurafenib and dabrafenib, revolutionized the treatment of $B R A F^{\mathrm{V} 600 \mathrm{E}}$ metastatic melanoma and have been shown to be active in $B R A F^{\mathrm{V} 600 \mathrm{E}}$-mutated non-smallcell lung cancer, anaplastic thyroid cancer, cholangiocarcinoma, Erdheim-Chester disease, and Langerhans cell histiocytosis. ${ }^{39}$ Additionally, single-agent vemurafenib was shown to arrest cell proliferation and inhibit tumor growth in CRC cell lines and xenograft models expressing $B R A F^{\mathrm{V} 600 \mathrm{E}}$, respectively. ${ }^{40}$ Based on this, a Phase II pilot study of vemurafenib was completed in patients with $B R A F^{\mathrm{V} 600 \mathrm{E}}$ metastatic CR using the maximum tolerated dose of $960 \mathrm{mg}$ twice daily identified in melanoma studies. ${ }^{8}$ Of the 21 patients enrolled, a partial response was documented in one patient and seven patients were reported to have stable disease; however, the median PFS of 2.1 months did not suggest durable activity from single-agent BRAF inhibition. Similar to the rates seen in melanoma treatment, 15 of the 21 (71\%) patients experienced a grade 3 adverse event, including development of five squamous cell carcinomas of the skin, a known adverse event associated with single-agent BRAF inhibition.

Pharmacokinetic evaluations suggest that the discordant responses between the two diseases are due to marked differences in underlying tumor biology. In contrast to CRC, melanoma cells are not epithelial cells and do not typically express epidermal growth factor. The lack of response of $B R A F^{\mathrm{V} 600 \mathrm{E}} \mathrm{CRC}$ to single-agent $B R A F$ inhibition has been hypothesized to be due at least in part to feedback activation of EGFR resulting in MAPK signaling pathway reactivation. ${ }^{41,42}$ In vitro and in vivo models have shown decreased MAPK signaling and increased response with combined inhibition of BRAF and EGFR. ${ }^{40-42}$

Based on this hypothesis, 15 patients with $B R A F^{\mathrm{V} 600 \mathrm{E}}$ metastatic CRC who had previously progressed on prior chemotherapy were enrolled to a pilot study of vemurafenib plus panitumumab, both at previously approved doses. ${ }^{43}$ Initial 
Table I Completed trials of targeted therapies in metastatic CRC with a BRAF ${ }^{\mathrm{V} 600 \mathrm{E}}$ mutation

\begin{tabular}{|c|c|c|c|c|c|}
\hline Trial & Reference & Trial design & Intervention arm & Control arm & Summary of results \\
\hline NCT00405587 & Kopetz et $\mathrm{al}^{8}$ & $\begin{array}{l}\text { Open label, } \\
\text { Phase II, single } \\
\text { arm }\end{array}$ & $\begin{array}{l}\text { Vemurafenib } 960 \mathrm{mg} \text { BID } \\
(\mathrm{N}=2 \mathrm{I})\end{array}$ & NA & $\begin{array}{l}\text { One partial response }(5 \%) \text {; seven } \\
\text { patients with stable disease. Median PFS } \\
\text { of } 2.1 \text { months }\end{array}$ \\
\hline NCT0I072I75 & Corcoran et $\mathrm{al}^{44}$ & $\begin{array}{l}\text { Open label, } \\
\text { Phase I/II single } \\
\text { arm }\end{array}$ & $\begin{array}{l}\text { Dabrafenib ( } 150 \mathrm{mg} \text { BID) } \\
\text { plus trametinib ( } 2 \mathrm{mg} \text { daily) } \\
(\mathrm{N}=43)\end{array}$ & NA & $\begin{array}{l}\text { Five patients ( } 12 \% \text { ) sustained a partial } \\
\text { response or better; } 24 \text { patients (56\%) } \\
\text { with stable disease }\end{array}$ \\
\hline NCT0I7509I8 & Corcoran et $\mathrm{al}^{46}$ & $\begin{array}{l}\text { Open label, } \\
\text { Phase I/II }\end{array}$ & $\begin{array}{l}\text { Dabrafenib } 150 \mathrm{mg} \mathrm{BID} \text {, } \\
\text { trametinib } 2 \mathrm{mg} \text { daily, and } \\
\text { panitumumab } 6 \mathrm{mg} / \mathrm{kg} \\
\text { every } 14 \text { days }(\mathrm{N}=35)\end{array}$ & $\begin{array}{l}\text { Dabrafenib } \\
50 \text { mg BID and } \\
\text { panitumumab } 6 \mathrm{mg} / \\
\text { kg every } 14 \text { days } \\
(\mathrm{N}=20)\end{array}$ & $\begin{array}{l}\text { Response rate in three-drug } \\
\text { combination was } 26 \% \text {, with an additional } \\
57 \% \text { of patients achieving stable disease }\end{array}$ \\
\hline NCTOI7I9380 & van Geel et al ${ }^{50}$ & $\begin{array}{l}\text { Phase lb dose } \\
\text { escalation }\end{array}$ & $\begin{array}{l}\text { Encorafenib + cetuximab } \\
+ \text { alpelisib, with escalating } \\
\text { doses }(\mathrm{N}=28)\end{array}$ & $\begin{array}{l}\text { Encorafenib }+ \\
\text { cetuximab }(\mathrm{N}=26)\end{array}$ & $\begin{array}{l}\text { Overall response rates of } 19 \% \text { and } \\
18 \% \text { were confirmed in two-drug and } \\
\text { three-drug combinations, respectively. } \\
\text { Median PFS was } 3.7 \text { and } 4.2 \text { months for } \\
\text { two-drug and three-drug combinations, } \\
\text { respectively }\end{array}$ \\
\hline NCT02164916 & Kopetz et $\mathrm{al}^{52}$ & $\begin{array}{l}\text { Randomized } \\
\text { Phase II }\end{array}$ & $\begin{array}{l}\text { Irinotecan }\left(180 \mathrm{mg} / \mathrm{m}^{2}\right) \\
\text { and cetuximab }(500 \mathrm{mg} / \\
\left.\mathrm{m}^{2}\right) \text { every I } 4 \text { days, plus } \\
\text { vemurafenib }(960 \mathrm{mg} \text { PO } \\
\mathrm{BID})(\mathrm{N}=54)\end{array}$ & $\begin{array}{l}\text { Irinotecan }(180 \mathrm{mg} / \\
\left.\mathrm{m}^{2}\right) \text { and cetuximab } \\
\left(500 \mathrm{mg} / \mathrm{m}^{2}\right) \text { every } \\
14 \text { days }(\mathrm{N}=52)\end{array}$ & $\begin{array}{l}\text { Median PFS } 4.4 \text { vs } 2.0 \text { months (HR } 0.42 \text {; } \\
95 \% \mathrm{Cl} 0.26-0.66 ; P<0.00 \mathrm{I}) \text {. ORR I6 vs } \\
4 \%(P=0.09) \text {. Disease control rate of } 67 \\
\text { vs } 22 \%(P<0.00 \mathrm{I})\end{array}$ \\
\hline
\end{tabular}

Abbreviations: BID, twice a day; CRC, colorectal cancer; HR, hazard ratio; NA, not applicable; ORR, overall response rate; PFS, progression-free survival; PO, by mouth.

responses were encouraging, with some tumor regression seen in 10 of the 12 evaluable patients and less cutaneous toxicity than would be expected with either single agent.

In another attempt to inhibit signaling through the MAPK pathway, a single-arm study treated 43 patients with $B R A F^{\mathrm{V} 600 \mathrm{E}}$ metastatic $\mathrm{CRC}$ with the combination of dabrafenib and the $M E K$ inhibitor trametinib. ${ }^{44}$ Responses were improved compared to single-agent BRAF inhibition, with $12 \%$ of patients achieving a partial response or better and $56 \%$ with stable disease. Of note, there was one complete response, with the duration of response of $>36$ months, and 10 patients remained on study beyond 6 months. Adverse events were overall similar to what has been seen with combined BRAF and MEK inhibition in melanoma, notably with pyrexia occurring in $30 \%$ of patients and being the most common cause of treatment delay and dose reductions.

These approaches to MAPK signaling inhibition were combined in a Phase I/II clinical trial, which enrolled patients with $B R A F^{\mathrm{V} 600 \mathrm{E}} \mathrm{CRC}$ to the combination of dabrafenib, trametinib, and panitumumab. ${ }^{45}$ In the Phase I component, there were no dose-limiting toxicities and the most common adverse event was acneiform dermatitis. The Phase II expansion of this study then compared the dabrafenib, trametinib, and panitumumab triplet with doublets of either dabrafenib plus panitumumab or trametinib plus panitumumab. In the trametinib plus panitumumab arm, there were no confirmed responses, suggesting that inhibition of $B R A F$ is necessary but not sufficient for response. The response rate to dabrafenib plus panitumumab arm was $10 \%$ (95\% CI 1.2-31.7) compared to $21 \%(95 \%$ CI $12.5-43.3)$ for the triplet arm. ${ }^{46}$ For the 91 patients treated with triplet therapy, disease control (response plus stable disease rates) was achieved in $86 \%$ of patients, with a median duration of response of 7.6 months and a median PFS of 4.2 months. ${ }^{47}$ These results suggest a role for combined targeted therapies as a therapeutic option for $B R A F$ mutant disease (Figure 1).

Activation of the PI3K/AKT pathway has also been shown in $B R A F^{\mathrm{V} 600 \mathrm{E}} \mathrm{CRC}$ cell lines to mediate both innate and acquired resistances to $B R A F$ inhibition. ${ }^{48}$ Preclinical work confirmed that combining blockade of PI3K $\alpha$, BRAF, and EGFR resulted in synergistic antiproliferative effects in vitro and tumor regression in xenograft models. ${ }^{49}$ This spurred a Phase Ib/II study evaluating the RAF inhibitor encorafenib in combination with cetuximab with or without the PI3K $\alpha$ inhibitor alpelisib in $B R A F^{\mathrm{v} 600 \mathrm{E}}$ metastatic CRC. ${ }^{50}$ Although high rates of grade III/IV adverse effects of $69 \%$ in the twodrug arm and $79 \%$ in the three-drug arm were reported, the maximum tolerated dose was not reached in either arm. ${ }^{50}$ The overall response rates in the 54 patients treated were 19 and $18 \%$ in the two- and three-drug arms, with a median PFS of 3.7 and 4.2 months, respectively. ${ }^{50}$ Of note, this was a heavily pretreated population with the majority of patients having received two or more prior lines of therapy and $>25 \%$ having received prior anti-EGFR therapy. 


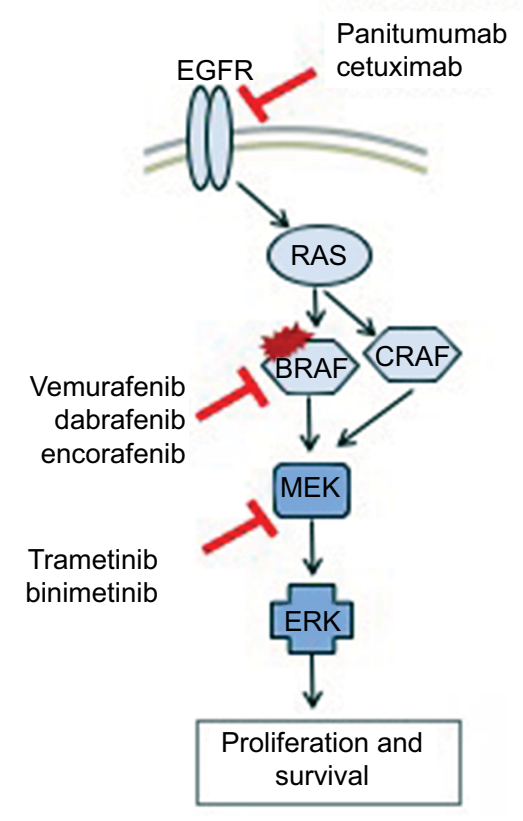

Figure I Targeted therapy approaches in clinical trials for BRAF ${ }^{\mathrm{V} 600 \mathrm{E}}$ mutant $\mathrm{CRC}$. Abbreviation: $\mathrm{CRC}$, colorectal cancer.

Concurrently with the development of targeted therapies, a Phase $1 \mathrm{~b}$ study evaluated the combination of targeted therapies in combination with chemotherapy with a threedrug regimen of vemurafenib, cetuximab, and irinotecan. ${ }^{51}$ The combination was well tolerated with the most common adverse effects being fatigue, diarrhea, nausea, and rash, and responses were seen in $35 \%$ of evaluable patients. This led to the Phase II Southwest Oncology Group (SWOG) 1406 trial, the first-ever randomized controlled trial in $B R A F^{\mathrm{V} 600 \mathrm{E}}$-mutant metastatic CRC, evaluating irinotecan plus cetuximab with or without vemurafenib. ${ }^{52}$ The primary endpoint was PFS, and cross-over to the experimental arm with vemurafenib was allowed. With heightened awareness and increased testing for $B R A F^{\mathrm{V} 600 \mathrm{E}}$ among local oncology providers, accrual to SWOG 1406 was swifter than projected; 106 patients enrolled in $<1.5$ years. Reflecting the insight of the investigators' awareness of the unique challenges of measuring peritoneal metastasis and ascites in this patient population, SWOG 1406 included patients with nonmeasurable disease according to the RECIST 1.1 criteria. SWOG 1406 reported a median PFS of 4.4 vs 2.0 months for the threedrug regimen (irinotecan, cetuximab, and vemurafenib) vs the two-drug regimen (irinotecan and cetuximab) (HR 0.42; 95\% CI $0.26-0.55 ; P<0.001)$. Response rates in this study were 16 vs $4 \%$, respectively ( $P=0.09$ ). Of note, neutropenia, anemia, and nausea occurred more frequently in the arm that included vemurafenib; however, the proportions of patients who developed rash and fatigue were comparable.
Correlative laboratory studies performed in conjunction with these studies provide a sobering reminder of how little we know. A study of molecular alterations in paired exposure biopsies obtained before and after exposure to BRAF inhibition showed acquisition of KRAS amplification, BRAF amplification, and MEK1 mutation following exposure to BRAF inhibitors. ${ }^{53}$ Similarly, analysis of circulating tumor DNA revealed the emergence of $R A S$ mutations at disease progression in nearly half of patients following treatment with dabrafenib, trametinib, and panitumumab. ${ }^{47}$ Each of these alterations results in reactivation of the MAPK pathway, and these findings point to the critical importance of signaling through this pathway for the growth of $B R A F^{\mathrm{V} 600 \mathrm{E}}$-mutant CRC cells. Additionally, analysis of pERK suppression from tumor samples after treatment with the combination of dabrafenib, trametinib, and panitumumab showed less suppression than what is seen with treatment with dabrafenib alone in melanoma, suggesting that we are currently still unable to inactivate MAPK pathway signaling in $B R A F^{\mathrm{V} 600 \mathrm{E}_{-}}$ mutant CRC. This pathway dependence intimates that ongoing efforts to inhibit MAPK signaling may be necessary to achieve improvements in clinical response.

\section{The intersection of BRAF and MSI}

As noted earlier, there is a significant overlap between $B R A F^{\mathrm{V} 600 \mathrm{E}}$ and sporadic high-level MSI in CRC. In previously completed randomized trials, $16-33 \%$ of MSI-high tumors also harbored $B R A F^{\mathrm{V} 600 \mathrm{E}}$ mutations. ${ }^{44,46,50} \mathrm{In}$ a population-based cohort of 1,253 patients, $52 \%$ of the 193 MSI-high cases were also $B R A F$ mutant, while $55 \%$ of the $B R A F$ mutant cases were also MSI-high. ${ }^{26}$ In this population, MSI-high status was associated with significantly lower CRC-specific mortality (multivariable HR $=0.28,95 \%$ CI $0.17-0.46 ; P<0.001$ ) and the presence of a $B R A F^{\mathrm{V} 600 \mathrm{E}}$ mutation was associated with significantly higher CRC-specific mortality (multivariable $\mathrm{HR}=1.64$, 95\% CI 1.18-2.27; $P=0.003$ ), as seen in other studies. Within each subgroup, MSI and $B R A F^{\mathrm{V} 600 \mathrm{E}}$ status remained prognostic, such that $B R A F^{\mathrm{V} 600 \mathrm{E}}$ was associated with higher mortality in both MSS and MSI-high patients, and MSI-high tumors were associated with decreased mortality in both $B R A F$-wild-type and -mutated patients. ${ }^{26}$ These results suggest that the presence of a $B R A F^{\mathrm{V} 600 \mathrm{E}}$ mutation may diminish the more favorable prognosis afforded by MSI-high status in metastatic CRC.

However, it is not clear that this relationship holds true for stage III CRC, where studies have had conflicting results. A study performed on tumor specimens from the Intergroup 0135 trial for stage III CRC found that MSI-high and $B R A F$-wild-type patients had the best long-term survival 
but found no differences between MSI-high/BRAF$F^{\mathrm{V} 600 \mathrm{E}}$ mutant, MSS $/ B R A F^{\mathrm{V} 600 \mathrm{E}}$-mutant, and $\mathrm{MSS} / B R A F$-wild-type patients. ${ }^{54} \mathrm{~A}$ similar analysis performed on specimens from the adjuvant CALGB 89803 trial also showed that MSI-high and $B R A F$-wild-type tumors are associated with the best prognosis but identified MSI/BRAF $F^{\mathrm{V} 600 \mathrm{E}}$-mutant and MSS/ $B R A F$-wild-type patients to have an intermediate prognoses, while $\mathrm{MSS} / B R A F^{\mathrm{V} 600 \mathrm{E}}$-mutant patients have the worst prognosis. ${ }^{55}$ This finding parallels findings from patients with metastatic CRC.

The recent US Food and Drug Administration (FDA) approvals of two checkpoint inhibitors, pembrolizumab and nivolumab, for the treatment of MSI-high metastatic CRC transformed the therapeutic landscape for the small subset of metastatic CRC patients with MSI-high tumors ( $\sim 4 \%)$. Given the substantial overlap between MSI-high status and BRAF mutation, there is a considerable interest in the application of checkpoint inhibitors in the subset of patients with MSIhigh $B R A F^{\mathrm{V} 600 \mathrm{E}} \mathrm{CRC}$.

Pembrolizumab is a monoclonal antibody against the programed death receptor 1 (PD-1), which has been shown to increase immune recognition of tumor across a variety of tumor types. In a Phase II study of pembrolizumab given to $10 \mathrm{MSI}-$ high and $18 \mathrm{MSS}$ metastatic CRC patients, the response rates were 40 and $0 \%$, respectively. ${ }^{56}$ This led to an expansion cohort for a total of $28 \mathrm{MSI}$-high patients, in whom the response rate was 50\% (95\% CI $31-69 \%) .{ }^{57}$ Median PFS had not been reached at the time of presentation at the 2016 ASCO Annual Meeting. However, there were no identified patients with $B R A F$ mutations in this cohort; thus, it is not yet clear from this study if presence of a $B R A F^{\mathrm{V} 600 \mathrm{E}}$ was associated with the likelihood of response.

Nivolumab, the second checkpoint inhibitor to be FDA approved for MSI-high metastatic CRC, is also a monoclonal antibody directed against PD-1. The Phase II Checkmate-142 study reported a $31 \%(95 \%$ CI $20.8-42.9)$ response rate and a 69\% (95\% CI 57-79) disease control rate in 74 MSI-high metastatic CRC patients treated with nivolumab. ${ }^{58}$ Similar to what has been seen in other studies of checkpoint blockade, responses were often durable and median PFS has not yet been reported. Of the $16 \%$ of patients with a $B R A F$ mutation $(\mathrm{n}=12)$, an objective response was seen in $25 \%$. Although this response rate is similar to what has thus far been observed with the aforementioned targeted $B R A F$ inhibition combinations, the possibility of durable disease control may be much higher with checkpoint inhibition; this remains an area of active investigation.

\section{The role for metastectomy}

Finally, our review would not be completely without mention of the management of oligometastatic disease. Distinct from other cancer types, CRC is one of the rare solid tumors where cure is feasible in the presence of limited metastatic disease. ${ }^{59}$ However, careful selection for metastasectomy is widely acknowledged as a predictor for the benefit of surgical intervention. Relevant to this discussion is whether the detection of $B R A F^{\mathrm{V} 600 \mathrm{E}}$ mutation should deter providers from pursuing metastectomy.

In a single-center retrospective study of 92 patients, the presence of $B R A F^{\mathrm{V} 600 \mathrm{E}}$ was associated with less frequent presentations of liver-limited disease ( 41 vs $63 \% ; P<0.01$ ) and, not surprisingly, fewer patients with a $B R A F^{\mathrm{V} 600 \mathrm{E}}$ mutation were candidates for metastectomy ( 41 vs $26 \% ; P<0.01) .{ }^{20}$ Among those patients with $B R A F^{\mathrm{V} 600 \mathrm{E}}$ tumors who underwent metastectomy, a trend toward shorter recurrence-free survival after metastectomy ( 7 vs 11 months, $P=0.084$ ) and a significantly shorter OS (2-year OS 61 vs $86 \% ; P=0.003$ ) were reported. Additionally, of the 20 patients with $B R A F^{\mathrm{V} 600 \mathrm{E}}$ mutations who underwent resection with curative intent (15 for liver metastases, four for lung metastases, and one for ovarian metastasis), 18 (90\%) patients developed recurrence.

Given the high risk of recurrence after metastectomy in this population, along with the potential morbidity of surgery, we recommend metastectomy only in very carefully selected patients who have truly liver-limited disease and have previously achieved durable disease control in response to systemic therapy.

\section{Future directions}

Reflecting the rapid evolution of efforts for this small subset of CRC patients, the first-ever Phase III study is now underway evaluating the combination of BRAF, EGFR, and MEK inhibition (Figure 2). ${ }^{46}$ The Phase III BEACON CRC study is currently enrolling patients with $B R A F^{\mathrm{V} 600 \mathrm{E}}$ metastatic CRC to evaluate the combination of encorafenib, cetuximab, and the MEK inhibitor binimetinib. ${ }^{60}$ In the initial safety lead-in, 30 patients received triplet therapy with good tolerability and a confirmed overall response rate of $41 \% .{ }^{61}$ Additionally, there is suggestion of a possibly more durable response than has previously been seen with BRAF inhibition, with $76 \%$ of patients remaining on study at a median of 5.6 months of treatment. The Phase III component is currently enrolling to the three arms of encorafenib plus cetuximab vs encorafenib, cetuximab and binimetinib vs FOLFIRI, or irinotecan plus cetuximab (at the discretion of 


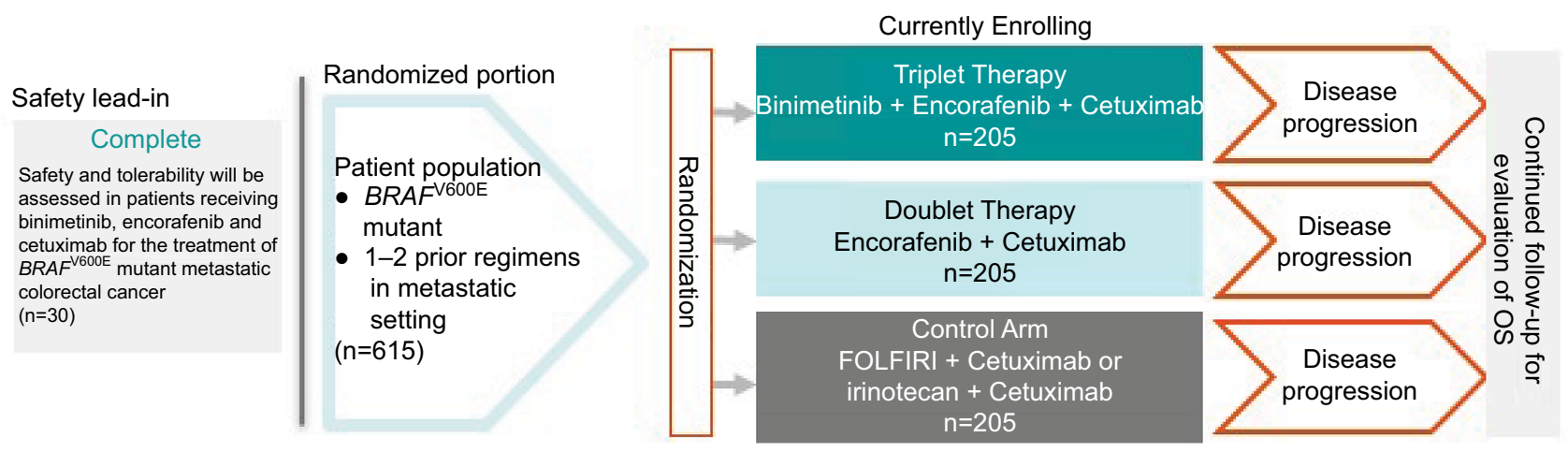

Figure 2 Schematic representation of the Phase III study of encorafenib + cetuximab plus or minus binimetinib vs irinotecan/cetuximab or infusional 5-FU/FA/irinotecan (FOLFIRI)/cetuximab with a safety lead-in of encorafenib + binimetinib + cetuximab in patients with BRAF ${ }^{\mathrm{V} 600 \mathrm{E}}$-mutant metastatic CRC (BEACON CRC).

Abbreviations: CRC, colorectal cancer; FA, folinic acid; 5-FU, 5-fluorouracil; FOLFIRI, 5-fluorouracil, leucovorin and irinotecan.

the investigator) (NCT02928224). BEACON will potentially serve as a licensing trial for BRAF-inhibitor-based combination therapy for metastatic CRC but is not projected to reach its accrual goal until 2019.

Further efforts to elucidate other mechanisms of resistance to BRAF inhibition are an area of active investigation. As an example, researchers have identified increased Wnt pathway signaling as potentially cooperating with signaling through the MAPK pathway to sustain $B R A F^{\mathrm{V} 600 \mathrm{E}}$ tumor growth. We are currently awaiting results of NCT02278133, which has completed the enrollment of patients with both $B R A F^{\mathrm{V} 600 \mathrm{E}}$ and Wnt pathway mutations who were treated with the Wnt inhibitor WNT974 in combination with encorafenib and cetuximab. ${ }^{62}$

Finally, clinical trials combining therapies targeting the MAPK pathway with immunotherapy are in development.

\section{Summary of recommendations for clinical practice}

Acknowledging that most data guiding the management of patients with metastatic $B R A F^{\mathrm{V} 600 \mathrm{E}} \mathrm{CRC}$ are based upon small sample sizes and that the management of this condition is dynamic, the following clinical recommendations represent a compilation from the currently available data, existing clinical practice guidelines, as well as our own clinical experiences.

- Current NCCN guidelines recommend genomic testing to specifically include $B R A F$ testing at the time of diagnosis of metastatic CRC. ${ }^{31}$ The testing can be done either on the primary tumor or on tissue from a metastatic site, as the results for this gene have been shown to be highly concordant. ${ }^{63}$ With improved recognition of poor prognosis and distinct clinical features of this population, earlier identification of a $B R A F^{\mathrm{V} 600 \mathrm{E}}$ mutation may expand therapeutic and/or clinical trial options before a patient faces clinical deterioration.

- For fit patients with a de novo presentation of metastatic CRC with $B R A F^{\mathrm{V} 600 \mathrm{E}}$ mutation for whom a clinical trial is not immediately available, we recommend considering FOLFOXIRI plus bevacizumab as first-line therapy in effort to obtain disease control.

- The likelihood of response from anti-EGFR monotherapies is low, and we recommend against the use of antiEGFR therapy in patients with a known $B R A F^{\mathrm{V} 600 \mathrm{E}}$ tumor $^{31}$ outside of the context of a clinical trial, particularly for those with right-sided primary tumors.

- For MSI-high tumors harboring a $B R A F^{\mathrm{V} 600 \mathrm{E}}$ mutation, we recommend treatment with a checkpoint inhibitor treatment prior to considering BRAF-targeted therapy due to the higher potential for durable disease control; however, we acknowledge that checkpoint inhibitors and targeted therapies have not been studied in a head-to-head comparison.

- For MSS tumors harboring a $B R A F^{\mathrm{V} 600 \mathrm{E}}$ mutation or for patients with MSI-high $B R A F^{\mathrm{V} 600 \mathrm{E}}$-mutated tumors who have previously progressed on a checkpoint inhibitor, we recommend enrollment on a clinical trial when feasible. However, we acknowledge that access to a tertiary medical center is not available to all patients.

- Pending results of the ongoing Phase III BEACON trial, the sum of data to date support the hypothesis that while targeted agents appear to be inactive as monotherapies in $B R A F^{\mathrm{V} 600 \mathrm{E}}$-mutant $\mathrm{CRC}$, combinations of BRAF, MEK, and other pathway inhibitors may have at least temporary efficacy. Access to these medications is currently not FDA approved for the treatment of metastatic $B R A F^{\mathrm{V} 600 \mathrm{E}} \mathrm{CRC}$; 
however, off-label use of these combinations merits consideration and is substantiated by a growing body of literature. In view of this, January 2018 updates to the NCCN Colorectal Guidelines included new recommendations regarding the treatment of these patients and off-label usage is likely to be more readily available. Currently, our preferred combinations include dabrafenib, trametinib, and panitumumab, ${ }^{41}$ or vemurafenib, cetuximab, and irinotecan, ${ }^{47}$ with selection based upon toxicity profiles.

- In highly selected patients with very limited liver-only metastasis(es), curative intent metastectomy can be considered. However, patients should be counseled extensively on the high risk of recurrence following any surgical intervention.

\section{Conclusion}

The personalization of cancer care is rooted in the premise that there are subsets of patients with tumors harboring clinically relevant targets for patient-specific treatments. CRC is historically a disease that has been notable for its dearth of biomarkers that are predictive of response to targeted therapies. In a rapidly evolving era of personalized oncology, CRC has been eclipsed by other tumor types, with very little of the abundant genomic data bearing any relevance for clinical decision-making. $B R A F^{\mathrm{V} 600 \mathrm{E}}$-mutated $\mathrm{CRC}$ is an exception, however, and considerable progress has been made in recent years to enhance both our understanding of the biology of $B R A F^{\mathrm{V} 600 \mathrm{E}}$-mutant metastatic $\mathrm{CRC}$ and the associated therapeutic landscape.

While the overall prognosis for $B R A F^{\mathrm{V} 600 \mathrm{E}}$ mutant metastatic CRC is still far worse than for $B R A F$-wild-type CRC, the incremental progress thus far should be credited to the consistent incorporation of robust, high-quality correlative science into the clinical trials of BRAF inhibition and rapid translation of laboratory discovery into clinical trial design. Still, despite multiple studies showing evidence of response to combined BRAF/EGFR and BRAF/MEK inhibition, reported overall response rates and median PFS are modest at best, providing a sobering reminder of the ongoing need for therapeutic development for this disease. Looking ahead, we remain optimistic that ongoing efforts to impede signaling through the MAPK pathway through alternate targets will result in longer and more durable clinical responses for this unique subset of patients.

\section{Acknowledgments}

CU's fellowship training in the Division of Hematology and Oncology at UCSF is supported by the Maisin Foundation and grant T32 AG000212 from the National Institute of Aging/Research Training in Geriatric Medicine. CEA is supported by the NIH and NCI under Award Number K08CA175143.

\section{Disclosure}

CEA is a consultant/advisory board member for Genentech/ Roche and has received research funding from Novartis. The authors report no other conflicts of interest in this work.

\section{References}

1. Stewart BW, Wild CP [webpage on the Internet]. World Cancer Report 2014. 2017. Available from: http://publications.iarc.fr/Non-SeriesPublications/World-Cancer-Reports/World-Cancer-Report-2014. Accessed July 18, 2017.

2. NIH [webpage on the Internet]. Cancer of the Colon and Rectum-SEER Stat Fact Sheets. 2016. Available from: https://seer.cancer.gov/statfacts/ $\mathrm{html} /$ colorect.html. Accessed December 22, 2016.

3. WHO [webpage on the Internet]. Cancer. WHO; 2017. Available from: http://www.who.int/mediacentre/factsheets/fs297/en/. Accessed October $15,2017$.

4. Davies H, Bignell GR, Cox C, et al. Mutations of the BRAF gene in human cancer. Nature. 2002;417(6892):949-954.

5. Flaherty KT, Puzanov I, Kim KB, et al. Inhibition of mutated, activated BRAF in metastatic melanoma. N Engl J Med. 2010;363(9):809-819.

6. Hauschild A, Grob J-J, Demidov LV, et al. Dabrafenib in BRAF-mutated metastatic melanoma: a multicentre, open-label, phase 3 randomised controlled trial. Lancet. 2012;380(9839):358-365.

7. Sullivan RJ, Weber JS, Patel SP, et al. A phase Ib/II study of BRAF inhibitor (BRAFi) encorafenib (ENCO) plus MEK inhibitor (MEKi) binimetinib (BINI) in cutaneous melanoma patients naive to BRAFi treatment. J Clin Oncol. 2015;33(15_suppl):9007.

8. Kopetz S, Desai J, Chan E, et al. Phase II pilot study of vemurafenib in patients with metastatic BRAF-mutated colorectal cancer. J Clin Oncol. 2015;33(34):4032-4038.

9. Chang K, Creighton CJ, Davis C, et al. The Cancer Genome Atlas PanCancer analysis project. Nat Genet. 2013;45(10):1113-1120.

10. English DR, Young JP, Simpson JA, et al. Ethnicity and risk for colorectal cancers showing somatic BRAF V600E mutation or CpG island methylator phenotype. Cancer Epidemiol Biomarkers Prev. 2008;17(7):1774-1780.

11. Muzny DM, Bainbridge MN, Chang K, et al. Comprehensive molecular characterization of human colon and rectal cancer. Nature. 2012;487(7407):330-337.

12. Barras D, Missiaglia E, Wirapati P, et al. BRAF V600E mutant colorectal cancer subtypes based on gene expression. Clin Cancer Res. 2017;23(1):104-115.

13. Zheng G, Tseng L-H, Chen G, et al. Clinical detection and categorization of uncommon and concomitant mutations involving BRAF. BMC Cancer. 2015;15(1):779.

14. Jones JC, Renfro LA, Al-Shamsi HO, et al. (Non-V600) BRAF mutations define a clinically distinct molecular subtype of metastatic colorectal cancer. J Clin Oncol. 2017;35(23):2624-2630.

15. Cremolini C, Di Bartolomeo M, Amatu A, et al. BRAF codons 594 and 596 mutations identify a new molecular subtype of metastatic colorectal cancer at favorable prognosis. Ann Oncol. 2015;26(10):2092-2097.

16. Tie J, Gibbs P, Lipton L, et al. Optimizing targeted therapeutic development: analysis of a colorectal cancer patient population with the BRAFV600E mutation. Int J Cancer. 2011;128(9):2075-2084.

17. Loupakis F, Moretto R, Aprile G, et al. Clinico-pathological nomogram for predicting BRAF mutational status of metastatic colorectal cancer. Br J Cancer. 2016;114(1):30-36. 
18. Yoon $\mathrm{HH}$, Shi Q, Alberts SR, et al. Racial differences in BRAF/KRAS mutation rates and survival in stage III colon cancer patients. $J$ Natl Cancer Inst. 2015;107(10):djv186.

19. Tran B, Kopetz S, Tie J, et al. Impact of BRAF mutation and microsatellite instability on the pattern of metastatic spread and prognosis in metastatic colorectal cancer. Cancer. 2011;117(20):4623-4632.

20. Yaeger R, Cercek A, Chou JF, et al. BRAF mutation predicts for poor outcomes after metastasectomy in patients with metastatic colorectal cancer. Cancer. 2014;120(15):2316-2324.

21. Atreya CE, Greene C, McWhirter RM, et al. Differential radiographic appearance of BRAF V600E-mutant metastatic colorectal cancer in patients matched by primary tumor location. J Natl Compr Canc Netw. 2016;14(12):1536-1543.

22. Maughan TS, Adams RA, Smith CG, et al. Addition of cetuximab to oxaliplatin-based first-line combination chemotherapy for treatment of advanced colorectal cancer: results of the randomised phase 3 MRC COIN trial. Lancet. 2011;377(9783):2103-2114.

23. Stintzing S, Miller-Phillips L, Modest DP, et al. Impact of BRAF and RAS mutations on first-line efficacy of FOLFIRI plus cetuximab versus FOLFIRI plus bevacizumab: analysis of the FIRE-3 (AIO KRK-0306) study. Eur J Cancer. 2017;79:50-60.

24. Venook AP, Niedzwiecki D, Lenz H-J, et al. Effect of first-line chemotherapy combined with cetuximab or bevacizumab on overall survival in patients with $K R A S$ wild-type advanced or metastatic colorectal cancer. JAMA. 2017;317(23):2392.

25. Innocenti F, Ou F-S, Zemla T, et al. Somatic DNA mutations, MSI status, mutational load (ML): association with overall survival (OS) in patients (pts) with metastatic colorectal cancer (mCRC) of CALGB/ SWOG 80405 (Alliance). J Clin Oncol. 2017;35(15_suppl):3504.

26. Lochhead P, Kuchiba A, Imamura Y, et al. Microsatellite instability and BRAF mutation testing in colorectal cancer prognostication. $J$ Natl Cancer Inst. 2013;105(15):1151-1156.

27. Roth AD, Tejpar S, Delorenzi M, et al. Prognostic role of KRAS and BRAF in stage II and III resected colon cancer: results of the translational study on the PETACC-3, EORTC 40993, SAKK 60-00 trial. J Clin Oncol. 2010;28(3):466-474.

28. Bokemeyer C, Van Cutsem E, Rougier P, et al. Addition of cetuximab to chemotherapy as first-line treatment for KRAS wild-type metastatic colorectal cancer: pooled analysis of the CRYSTAL and OPUS randomised clinical trials. Eur J Cancer. 2012;48(10):1466-1475.

29. Pietrantonio F, Petrelli F, Coinu A, et al. Predictive role of BRAF mutations in patients with advanced colorectal cancer receiving cetuximab and panitumumab: a meta-analysis. Eur J Cancer. 2015;51(5): 587-594.

30. Rowland A, Dias MM, Wiese MD, et al. Meta-analysis of BRAF mutation as a predictive biomarker of benefit from anti-EGFR monoclonal antibody therapy for RAS wild-type metastatic colorectal cancer. $\mathrm{Br} J$ Cancer. 2015;112(12):1888-1894.

31. Benson AB, Venook AP, Al-Hawary MM, et al. Colon Cancer, Version 1.2018. NCCN Clinical Practice Guidelines in Oncology. 2018. Available from: https://www.nccn.org/professionals/physician_gls/pdf/colon. pdf. Accessed February 3, 2018.

32. Venderbosch S, Nagtegaal ID, Maughan TS, et al. Mismatch repair status and BRAF mutation status in metastatic colorectal cancer patients: a pooled analysis of the CAIRO, CAIRO2, COIN, and FOCUS studies. Clin Cancer Res. 2014;20(20):5322-5330.

33. Seligmann JF, Fisher D, Smith CG, et al. Investigating the poor outcomes of BRAF-mutant advanced colorectal cancer: analysis from 2530 patients in randomised clinical trials. Ann Oncol. 2017;28(3):562-568.

34. Loupakis F, Cremolini C, Masi G, et al. Initial therapy with FOLFOXIRI and bevacizumab for metastatic colorectal cancer. $N$ Engl $J$ Med. 2014;371(17):1609-1618.

35. Cremolini C, Loupakis F, Antoniotti C, et al. FOLFOXIRI plus bevacizumab versus FOLFIRI plus bevacizumab as first-line treatment of patients with metastatic colorectal cancer: updated overall survival and molecular subgroup analyses of the open-label, phase 3 TRIBE study. Lancet Oncol. 2015;16(13):1306-1315.
36. Schmoll H-J, Meinert FM, Cygon F, et al. "CHARTA": FOLFOX/bevacizumab vs. FOLFOXIRI/bevacizumab in advanced colorectal cancer-final results, prognostic and potentially predictive factors from the randomized phase II trial of the AIO. J Clin Oncol. 2017;35(15_suppl):3533.

37. Goey KKH, Elias SG, van Tinteren H, et al. Maintenance treatment with capecitabine and bevacizumab versus observation in metastatic colorectal cancer: updated results and molecular subgroup analyses of the phase 3 CAIRO3 study. Ann Oncol. 2017;28(9):2128-2134.

38. Nakayama I, Shinozaki E, Matsushima T, et al. Retrospective study of RAS/PIK3CA/BRAF tumor mutations as predictors of response to first-line chemotherapy with bevacizumab in metastatic colorectal cancer patients. BMC Cancer. 2017;17(1):38

39. Hyman DM, Puzanov I, Subbiah V, et al. Vemurafenib in multiple nonmelanoma cancers with BRAF V600 mutations. $N$ Engl J Med. 2015;373(8):726-736.

40. Yang H, Higgins B, Kolinsky K, et al. Antitumor activity of BRAF inhibitor vemurafenib in preclinical models of BRAF-mutant colorectal cancer. Cancer Res. 2012;72(3):779-789.

41. Prahallad A, Sun C, Huang S, et al. Unresponsiveness of colon cancer to BRAF(V600E) inhibition through feedback activation of EGFR. Nature. 2012;483(7387):100-103.

42. Corcoran RB, Ebi H, Turke AB, et al. EGFR-mediated re-activation of MAPK signaling contributes to insensitivity of BRAF mutant colorectal cancers to RAF inhibition with vemurafenib. Cancer Discov. 2012;2(3):227-235.

43. Yaeger R, Cercek A, O'Reilly EM, et al. Pilot trial of combined BRAF and EGFR inhibition in BRAF-mutant metastatic colorectal cancer patients. Clin Cancer Res. 2015;21(6):1313-1320.

44. Corcoran RB, Atreya CE, Falchook GS, et al. Combined BRAF and MEK inhibition with dabrafenib and trametinib in BRAF V600-mutant colorectal cancer. J Clin Oncol. 2015;33(34):4023-4031.

45. Bendell JC, Atreya CE, André T, et al. Efficacy and tolerability in an open-label phase I/II study of MEK inhibitor trametinib (T), BRAF inhibitor dabrafenib (D), and anti-EGFR antibody panitumumab (P) in combination in patients (pts) with BRAF V600E mutated colorectal cancer (CRC). J Clin Oncol. 2014;32(15_suppl):3515.

46. Corcoran RB, Andre T, Atreya CE, et al. Combined BRAF, EGFR, and MEK inhibition in patients with BRAFV600E-mutant colorectal cancer. Cancer Discov. Epub 2018 Feb 05.

47. Corcoran RB, André T, Yoshino T, et al. Efficacy and circulating tumor DNA (ctDNA) analysis of the BRAF inhibitor dabrafenib (D), MEK inhibitor trametinib (T), and anti-EGFR antibody panitumumab (P) in patients (pts) with BRAF V600E-mutated (BRAFm) metastatic colorectal cancer (mCRC). Ann Oncol. 2016;27(suppl_6):4550.

48. Mao M, Tian F, Mariadason JM, et al. Resistance to BRAF inhibition in BRAF-mutant colon cancer can be overcome with PI3K inhibition or demethylating agents. Clin Cancer Res. 2013;19(3):657-667.

49. Caponigro G, Cao ZA, Zhang X, Wang HQ, Fritsch CM, Stuart DD. Abstract 2337: efficacy of the RAF/PI3K $\alpha /$ anti-EGFR triple combination LGX818 + BYL719 + cetuximab in BRAF ${ }^{\mathrm{V} 600 \mathrm{E}}$ colorectal tumor models. Cancer Res. 2013;73(8 suppl):2337-2337.

50. van Geel RMJM, Tabernero J, Elez E, et al. A phase Ib dose-escalation study of encorafenib and cetuximab with or without alpelisib in metastatic BRAF-mutant colorectal cancer. Cancer Discov. 2017;7(6):610-619.

51. Hong DS, Morris VK, El Osta BE, et al. Phase Ib study of vemurafenib in combination with irinotecan and cetuximab in patients with BRAFmutated metastatic colorectal cancer and advanced cancers. J Clin Oncol. 2015;33(15_suppl):3511.

52. Kopetz S, McDonough SL, Morris VK, et al. Randomized trial of irinotecan and cetuximab with or without vemurafenib in BRAFmutant metastatic colorectal cancer (SWOG 1406). J Clin Oncol. 2017;35(4_suppl):520.

53. Ahronian LG, Sennott EM, Van Allen EM, et al. Clinical acquired resistance to RAF inhibitor combinations in BRAF-mutant colorectal cancer through MAPK pathway alterations. Cancer Discov. 2015;5(4):358-367. 
54. French AJ, Sargent DJ, Burgart LJ, et al. Prognostic significance of defective mismatch repair and BRAF V600E in patients with colon cancer. Clin Cancer Res. 2008;14(11):3408-3415.

55. Ogino S, Shima K, Meyerhardt JA, et al. Predictive and prognostic roles of BRAF mutation in stage III colon cancer: results from intergroup trial CALGB 89803. Clin Cancer Res. 2012;18(3):890-900.

56. Le DT, Uram JN, Wang H, et al. PD-1 blockade in tumors with mismatch-repair deficiency. $N$ Engl J Med. 2015;372(26):2509-2520.

57. Le DT, Uram JN, Wang H, et al. Programmed death-1 blockade in mismatch repair deficient colorectal cancer. J Clin Oncol. 2016;34(15_suppl):103.

59. Overman MJ, McDermott R, Leach JL, et al. Nivolumab in patients with metastatic DNA mismatch repair-deficient or microsatellite instabilityhigh colorectal cancer (CheckMate 142): an open-label, multicentre, phase 2 study. Lancet Oncol. 2017;18(9):1182-1191.

59. Nordlinger B, Sorbye H, Glimelius B, et al. Perioperative FOLFOX4 chemotherapy and surgery versus surgery alone for resectable liver metastases from colorectal cancer (EORTC 40983): long-term results of a randomised, controlled, phase 3 trial. Lancet Oncol. 2013;14(12):1208-1215.
60. Huijberts S, Schellens JHM, Fakih M, et al. BEACON CRC (binimetinib [BINI], encorafenib [ENCO], and cetuximab [CTX] combined to treat BRAF-mutant metastatic colorectal cancer [mCRC]): a multicenter, randomized, open-label, three-arm phase III study of ENCO plus CTX plus or minus BINI vs irinotecan. J Clin Oncol. 2017;35(15_suppl):TS3622.

61. Huijberts S, Schellens JHM, Elez E, et al. 517PBEACON CRC: safety lead-in (SLI) for the combination of binimetinib (BINI), encorafenib (ENCO), and cetuximab (CTX) in patients (pts) with BRAF-V600E metastatic colorectal cancer (mCRC). Ann Oncol. 2017;28(suppl_5):mdx393.043.

62. ClinicalTrials.gov. Study of WNT974 in combination with LGX818 and cetuximab in patients with BRAF-mutant metastatic colorectal cancer $(\mathrm{mCRC})$ and Wnt pathway mutations - full text view - ClinicalTrials. gov. Available from: https://clinicaltrials.gov/ct2/show/NCT022781 33?term=NCT02278133\&rank=1. NLM identifier: NCT02278133. Accessed October 18, 2017.

63. Benson AB, Robert CH, Venook AP, et al. NCCN Guidelines Version 2.2017 Panel Members Colon Cancer MD/Vice-Chair UCSF Helen Diller Family Comprehensive Cancer Center. 2017. Available from: https://www.nccn. org/professionals/physician_gls/pdf/colon.pdf. Accessed August 9, 2017.
Gastrointestinal Cancer: Targets and Therapy

\section{Publish your work in this journal}

Gastrointestinal Cancer: Targets and Therapy is an international peer-reviewed, open access journal focusing on gastro-intestinal cancer research, identification of therapeutic targets and the optimal use of preventative and integrated treatment interventions to achieve improved outcomes, enhanced survival and quality of life for the

\section{Dovepress}

cancer patient. The manuscript management system is completely online and includes a very quick and fair peer-review system. Visit http://www.dovepress.com/testimonials.php to read real quotes from published authors.

Submit your manuscript here: https://www.dovepress.com/gastro-intestinal-cancer-targets-and-therapy-journal 